worth the theoretical gain in cancer control.

To return to the specific questions posed once again by Drs Price and Hill:

(1) The adjuvant chemotherapy proposed in the Cancer Research Campaign trial is the only one to date that has demonstrated a significant benefit in actual survival at 10 years. $^{6}$ No combination regimen has yet demonstrated the same. I await the actual 10-year results from the West Midlands oncology group and the Milan group with keen interest.

(2) I am not sure that I understand this question. Fifty per cent of my patients will die within 10 years after mastectomy, and if only I could predict which ones I would naturally not subject them to this mutilating procedure. The $10 \%$ improvement on this rate that I initially referred to was the level of improvement that one might modestly predict from the available data. Of course, the trial may show no benefit or even a benefit as high as $20 \%$. Whichever way it went I still could not predict prospectively which women would be the lucky ones. I presume that Drs Price and Hill do not have to face this dilemma when treating their patients as they know that al will benefit.

(3) As VPCMF has never been randomly compared with either tamoxifen or a short course of cyclophosphamide, I do not know how Drs Price and Hill can arrive at their prediction, particularly as I am not entirely confident that the cocktail would travel well to our underprivileged land.

Finally, as the "assent of the majority is the only sanction known to ethics," as Shaw said in his preface to The Doctor's Dilemma, the Cancer Research Campaign trial would be unethical in the United States as judged by the correspondence, but ethical in this country as judged by the large number of centres (35) already admitting patients. The clinicians participating in this trial are modest men seeking modest gains who want only to contribute to knowledge and relieving the suffering of womankind.

Michael Baum

Director, Cancer Research Campaign Clinical Trials Cent

Department of Surgery,

King's College Hospital Medical

London SE5 8RX

' Cooper RG, Holland JF, Glidewell O. Cancer 1979;

44:793-8.
Bonadonna G, Valagussa P. N Engl f Med $1981 ; 304$ :

$10-15$.
Popper KR. The logic

Hutchinson, 1959. Kardinal CG,

1979;6:396. ${ }^{5}$ Meakin JW, Allt WFC, Beale I:A, et al In: Salmon SE, Jones SE, eds. Adjuvant therapy of cancer. Amsterdam: Biomedical Press, Elsevier North Holland, 1977:95-9.

${ }^{6}$ Nissen-Meyer R, Kjeligren K, Malmio K, Mansson B, Norin T. Cancer 1978;41:2088-98.

${ }^{*}{ }^{*}$ This correspondence is now closed.-ED, $B M F$.

\section{Cancer of the cervix and screening}

SIR,-Largely as a result of certain programmes on the television and radio, the public have been given to understand that girls from the onset of sexual activity are in grave danger from cancer of the cervix uteri. It seems important that doctors should understand the size and nature of the problem, so that sensible decisions can be made about the use of resources. Table I shows the numbers of registered deaths from carcinoma of
TABLE I-Number of deaths attributed to cancer of the cervix

\begin{tabular}{|c|c|c|c|c|c|}
\hline Age & 1971 & 1973 & 1975 & 1977 & 1979 \\
\hline $20-24$ & 2 & 7 & 9 & 2 & 6 \\
\hline $25-29$ & 10 & 15 & 22 & 18 & 27 \\
\hline $\begin{array}{l}30-34 \\
25\end{array}$ & $\begin{array}{l}31 \\
52\end{array}$ & 24 & 46 & 53 & 56 \\
\hline $\begin{array}{l}35-39 \\
40-44\end{array}$ & $\begin{array}{r}52 \\
132 \\
\end{array}$ & $\begin{array}{l}54 \\
83\end{array}$ & $\begin{array}{l}58 \\
78\end{array}$ & $\begin{array}{l}74 \\
92\end{array}$ & $\begin{array}{l}79 \\
88\end{array}$ \\
\hline $45-49$ & 239 & 211 & 154 & 126 & 137 \\
\hline $50-54$ & 341 & 331 & 258 & 270 & 177 \\
\hline $55-59$ & 291 & 305 & 292 & 262 & 300 \\
\hline 60-64 & 303 & 300 & 305 & 308 & 278 \\
\hline & 271 & 263 & 276 & 277 & 281 \\
\hline $70-74$ & 226 & 237 & 225 & 241 & 233 \\
\hline $\begin{array}{l}75-79 \\
80-84\end{array}$ & $\begin{array}{l}196 \\
134\end{array}$ & $\begin{array}{l}209 \\
123\end{array}$ & $\begin{array}{l}206 \\
123\end{array}$ & $\begin{array}{l}193 \\
142\end{array}$ & $\begin{array}{l}195 \\
123\end{array}$ \\
\hline $85-95$ & & & 91 & 87 & 107 \\
\hline
\end{tabular}

the cervix in England and Wales in recent years, from which the different age groups can be compared.

It can be seen that though there has been a twofold to threefold increase in deaths in those under 35 in the past 10 years less than 100 deaths from this disease occur under that age, in contrast to over 2000 in women over that age-that is, 20 times as many. The corresponding age-specific rates (per million) are shown in table II.

It is known that over $50 \%$ of smears received in laboratories in this country are from women aged 16-34 years, a population of just over 7 million, while the 13 million above that age share the other $50^{\circ} \%{ }^{1}$ Probably nearly $80 \%$ of women under 35 are being screened, while there is a diminishing proportion beyond that age (perhaps less than $30^{\circ}$ ) who avail themselves of this facility.

It is the poor response, particularly in older women, which reduces the effect of the screening programme. The rate of invasive cervical cancer is in inverse ratio to the proportion of women screened in each age group. Of those who die of the disease, less than one in 10 appears ever to have had a cervical smear before the time of clinical presentation. $^{23}$ The British Columbia experience for many years has been similar, ${ }^{4}$ showing a 10 times greater risk of death from cancer of the cervix in the unscreened group.

The national effort should be directed towards identifying the non-responders, finding a cause for their non-response, and encouraging them to come forward.

\section{A M Adelstein}

Office of Population

Censuses and Surveys,
London WC2B 6JP

O A N HUSAIN

Regional Cytology Centre,

St Stephens Hospital,

A I SPRIGgS

Cytology 1)epartment,

Churchill Hospital,

Headington, Oxford

1 Office of Population Censuses and Surveys. Population estimates 1979. London: HMSO, 1980.

- Macgregor J E. Tumori 1976;62:287.

3 Spriggs AI, Boddington MA. Lancet 1976; : 143.

Fraser BJ, Boyes DA. In: Boström H, Larsson T Ljungstedt $\mathrm{N}$, eds. Health control in detection of cancer. Skandia International Symposia. Stockholm Almqvist and Wiksell, 1976.

TABLE II-OPCS mortality surveillance: age-specific death rates per million for cancer of the cervix

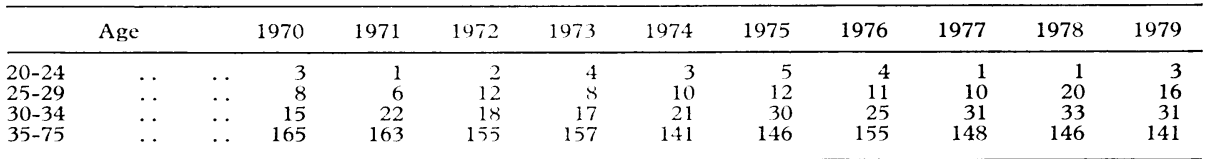

SIR,-The leading article on colposcopy (24 January, p 250) is well timed, and, while concurring with many of the ideas expressed, I was surprised at the omission of electrocoagulation in the discussion on conservative

Over the past five years, at the colposcopy clinic at Barnet General Hospital, I have used electrocoagulation in over 100 patients. The patient presenting with an abnormal smear has repeat cytology and colposcopy. Conservative treatment is offered when the whole lesion can be seen through the colposcope. On a day-case basis, under general anaesthesia, full curettage of the uterus and the endocervical canal is carried out together with biopsy of the abnormal areas followed by diathermy destruction of the lesion.

The colposcopist offering conservative treatment is committed to long-term follow-up -initially three monthly, but later at longer intervals, both by cytology and colposcopy as false-negative smears occur. This conservative treatment is offered only to young women wishing further children; to the older woman who has completed her family a liberal policy of hysterectomy, often vaginal, is offered. Using this format of electrocoagulation, Hollyock and Chanen show a $95 \%$ cure rate with a long-term follow-up.'

If laser-beam treatment can be shown to be as efficient, cheap, and as acceptable then perhaps we all ought to change over to this expensive, fashionable, and as yet unproved technique. Stafl et $a l^{2}$ using the laser have shown a $10 \%$ recurrence rate, and in an era of escalating costs all need be mindful of the cost-effectiveness of any treatment advocated.

Finally, who is the best person to be the colposcopist? I believe a gynaecologist trained in colposcopy and working closely with his colleagues in cytology and pathology. The gynaecologist after all can offer conservative treatment, cone biopsy, or hysterectomy if indicated as there may be other pathology in the pelvis or other factors to be considered in the overall management of the patient. He is also the best person to assess the cervix of the pregnant patient with abnormal cytology.

Barnet General Hospital,

H WAGMAN

$$
\begin{aligned}
& { }^{1} \text { Hollyock VE, Chanen W. Obstet Gynaecol 1976;47: } \\
& \text { 196-9. Wilkinson EJ, Mattingley RF. Am F Obstet } \\
& \text { 'Staf A, Wilkel } \\
& \text { Gynecol 1977; } \mathbf{1 2 8}: 128-36 .
\end{aligned}
$$

SIR,--May I respond to your leading article (24 January, p 250) on colposcopy? As one would expect, the sentiments expressed are sound, but their national publication is about three years late. Add to this the fact that no action can now be taken that will effectively control the growth of local colposcopy, and we have the usual British position of closing gates after horses have bolted-the "horse" in this case being the colposcope with the steady stimulus of a whip from the optical manutreatment of cervical intraepithelial neoplasia. 